\title{
Development of Nursing Research in Qatar: 15-Year Status Report
}

\author{
Abdulqadir J. Nashwan',2, Dana B. Mansour ${ }^{3}$, Abdulkarim Alzayyat4, Sindhumole K. Nair1, \\ Amer I. Zawahreh ${ }^{1}$ \\ ${ }^{1}$ National Center for Cancer Care \& Research (NCCCR)-Hamad Medical Corporation (HMC), Doha, Qatar \\ ${ }^{2}$ University of Calgary, Doha, Qatar \\ ${ }^{3}$ Qatar Cancer Society, Doha, Qatar \\ ${ }^{4}$ College of Nursing, University of Florida, Gainesville, FL, USA \\ Email: anashwan@hamad.qa, dana@qcs.qa, A.alzayyat@gmail.com,SNair10@hamad.qa, azawahreh@hamad.qa
}

How to cite this paper: Nashwan, A.J., Mansour, D.B., Alzayyat, A., Nair, S.K. and Zawahreh, A.I. (2017) Development of Nursing Research in Qatar: 15-Year Status Report. Open Journal of Nursing, 7, 242252.

https://doi.org/10.4236/ojn.2017.72020

Received: January 22, 2017

Accepted: February 21, 2017

Published: February 24, 2017

Copyright $\odot 2017$ by authors and Scientific Research Publishing Inc. This work is licensed under the Creative Commons Attribution International License (CC BY 4.0).

http://creativecommons.org/licenses/by/4.0/

\begin{abstract}
Purpose: The aim was to provide an overview of nursing research in Qatar over the previous 15 years. Methods: Several online databases were searched for published articles between 2000 and 2015 related to nursing research in Qatar. Findings: The initial search identified 6540 articles, whose titles, abstracts, and texts were screened for satisfying the eligibility criteria. Only 57 articles met the eligibility criteria. The highest percentage of studies (42\%) focused on clinical practice issues. Eighty-seven percent (87\%) were published in peer-reviewed journals; 84\% $(\mathrm{N}=48)$ were conducted between 2011 and 2015 with 16-fold growth rate compared to 2000-2005. The majority of authors were postgraduate qualified nurses, mainly $67 \%$ of them with hospital and academic affiliation (88\%). The vast majority of identified studies were conducted in hospital settings (63\%), and only $14 \%$ of the studies used a nursing theory or conceptual framework. Sixty-three percent $(63 \%)$ of the studies were quantitative, and $25 \%$ were funded mostly by hospitals. The majority of the included studies have been done in collaboration with other disciplines (60\%), especially with physicians (65\%). Conclusion: Nursing research in Qatar has dramatically developed and improved over the last 15 years. However, nurses need to be more motivated to conduct and publish research in collaboration with national, regional, and international research bodies. Implications for Nursing \& Health Policy: Building and sustaining nursing research infrastructure considered as a top priority for nursing leaders, academic, and ministry of public health in Qatar. Furthermore, preparing nurses with higher academic degrees is an essential step in advancing research utilization in Qatar and the region.
\end{abstract}

\section{Keywords}

Literature Review, Nursing, Research, Nurses, Qatar 


\section{Introduction}

From a global perspective, nursing research utilizes solid scientific methods that offer a robust body of knowledge for nursing practice advancement, health care policy establishment, and public health awareness promotion [1] [2]. The nursing research aims to enhance the overall wellbeing of the people as well as make health care providers informed about recent health care trends [3] [4]. The holistic approach is considered as one of the foundations of nursing research in which individuals', families' and communities' needs will be addressed [1]. This perspective involves an interdisciplinary and translational approach to science [5].

Nursing research priorities include promotion of the healthy lifestyles among the public, informing health care professionals about advanced health practices, maximizing the quality of the delivered care, and most importantly promoting the utilizing of evidence-based practice in nursing profession [4]. Nursing research can be defined broadly as "systematic inquiry designed to develop knowledge about issues of importance to the nursing profession, including nursing practice, education, administration, and informatics" [5]. On the other hand, a narrow definition of the nursing research could be "a scientific process that validates and refines existing knowledge and generates new knowledge that directly and indirectly influences clinical nursing practice" [6]. For an extended period of time, nursing has been considered as a vocation instead of a profession [7]. It has been reported by the nursing scholars that nursing knowledge has been borrowed from other fields such as sociology, psychology, and health sciences [2]. Nevertheless, most recently, a distinct body of knowledge has been established, and this assists in the identification of nursing as a unique profession [2]. Florence Nightingale is the first person who has recognized the necessity of collecting scientific data in nursing [8].

Clinical nursing research had been recommended early by Florence Nightingale in the mid-1800s; however; until more than 100 years later this recommendation was followed by the nursing bodies [9]. Studies about environmental health hazards are examples of the recent application of Florence Nightingale notions nowadays [8]. Furthermore, it is only recently that scholars have appreciated Florence Nightingale as distinguished women and scientist in the nursing field due to her contribution to the nursing profession [9]. Indeed, nursing profession can be developed, and distinct body of knowledge can be established if the nurses adhere to the recommendations of their ancient leaders [2].

It has been evident that educational level of nurses plays an important role in the growth of nursing research [5]. Since 1909, the United States had started to teach nursing profession as university-based degree; however, the growth of these educational programs was very slow [10]. From a different perspective, in the European countries, nursing programs had been started lately in the 1980s, but the number of these programs was progressing dramatically [11]. The evolution of nursing profession and inquiry in the Arab countries is relatively new compared to Europe and North America [12]. However, among the Middle East 
Arab countries, nursing research began early in Jordan, where the first nursing research paper was published in 1951 [13].

\section{Purpose and Significance}

The main aim of this review paper was to provide an overview of nursing research in the state of Qatar for the last 15 years. The following themes have been utilized to guide this review: the researched topic, affiliation of the authors, methodological aspects such as the source of data collection, as well as source of funding. The finding of this review could provide more information on the current status of nursing research in Qatar.

\section{Methodology}

\section{Search Strategy}

Several online databases were searched including: CINAHL (Cumulative Index to Nursing and Allied Health Literature), MEDLINE (Medical Literature onLine), Google Scholar, and PubMed. The following keywords were used: nursing, Qatar, research, nurses. All full-text articles of studies conducted in Qatar by nurses, in collaboration with nurses, or with nurse participants, published in English, and carried out between 2000 and 2015, were included in this review.

The initial search results included a total 6540 including research articles, academic works such as Master theses and Ph.D. dissertations, discussion papers, case studies, and conference abstracts. The titles, abstracts, and texts of these articles were screened for both inclusion and exclusion criteria. However, after applying the present review eligibility criteria, the authors included only 57 studies. Those included studies are associated with nursing profession in Qatar or carried out by nursing scholars lives in Qatar (see Figure 1).

After obtaining these articles from the Hamad Medical Library, the researchers read the abstract section for all of the 57 retrieved articles. A data extraction template was developed to assist in extracting the needed data from each article. The publication year, main topic, journal status (Peer-reviewed or not; national, regional or international), affiliation (e.g., academic, hospital, public health .. etc.), qualifications of nursing authors (e.g., BSN, MSN or PhD), methodology aspects like data collection, study settings, study language, funding source, and utilization of theoretical or conceptual framework and extent of collaboration with other disciplines were all recorded.

During the critical evaluation process, one of the researchers read and eva-

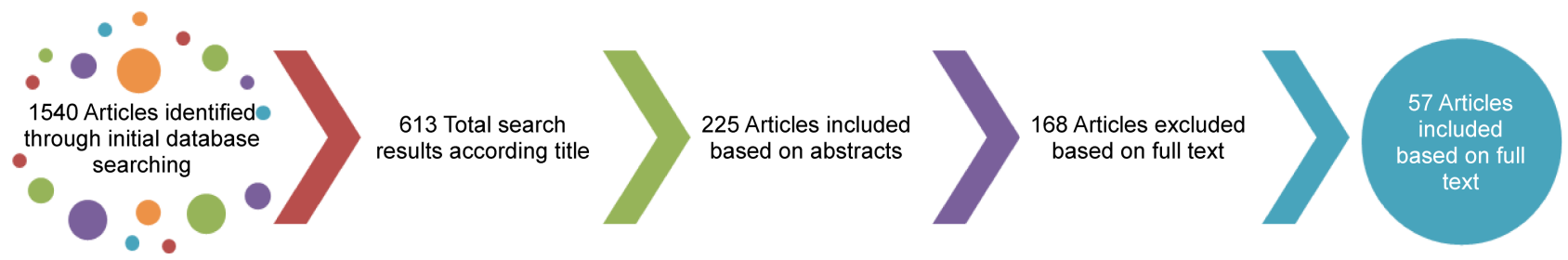

Figure 1. Selection process. 
luated each of the included articles; and the data extraction template was completed at this time. To validate this process, a research assistant reevaluated each of the included studies. Any identified discrepancies between these two evaluations were resolved through discussions and further clarification.

\section{Findings}

\subsection{Overview}

Five percent (5\%) of the included studies were published between 2000 and 2005 $(\mathrm{n}=3), 11 \%$ were published between 2006 and $2010(\mathrm{n}=6)$, and $84 \%$ of the articles were published between 2011 and $2015(n=48)$. This represents a 16-fold growth of the research rate from 2011 to 2015. In the next sections, the authors of this review paper will present the identified studies in accordance with the following themes: Journal type, professional affiliation and academic qualification, the source of data collection, theoretical or conceptual framework, funding source, collaboration with other researchers, study topic and study participants.

\subsection{Journal Type}

Eighty-seven (87\%) percent of the articles were published in peer-reviewed journals $(\mathrm{n}=47)$, and $13 \%$ of the articles were published in non-peer reviewed journals $(n=7)$. Three out of the 57 of the included articles were theses and dissertations that published on-line.

\subsection{Professional Affiliation and Academic Qualifications}

Eighty-eight (88\%) percent of the authors are affiliated with a hospital or academic institutions $(\mathrm{n}=50)$. Of these authors, $40 \%$ are affiliated with a hospital $(\mathrm{n}=23), 25 \%$ have academic affiliations $(\mathrm{n}=14)$, and $33 \%$ have multiple affiliations $(n=19)$. Only $2 \%$ of the authors have a community or public health affiliations $(\mathrm{n}=1)$.

From a different perspective, the majority of authors are postgraduate qualified nurses (67\%): $40 \%$ have a Ph.D. $(n=23)$, and $26 \%$ have a master's degree ( $n$ $=15)$. Concerning the authors who have an undergraduate degree, the results indicated that $12 \%$ of them are nurses with a Bachelor degree $(n=7)$ and $21 \%$ are researchers from non-nursing disciplines $(n=12)$.

\subsection{Sources of Data Collection}

It was observed that private healthcare sector research is still in its infancy compared with the governmental health care sector research initiatives in Qatar. Sixty-three (63\%) percent of the revised articles had samples drawn from hospitals ( $\mathrm{n}=36$ ), while only $12 \%$ had samples drawn from community settings ( $\mathrm{n}=$ 7 ) and only $8 \%$ had samples drawn from academic settings $(n=4)$. Five percent (5\%) of the studies recruited their samples from both hospital and community settings $(n=3)$. No sample was identified in $12 \%$ of the articles, as they were review articles $(n=7)$. 


\subsection{Theoretical or Conceptual Framework}

Of the 57 studies included in this review, 86\% did not use any nursing theory or conceptual framework to guide their research $(n=49)$. On the other hand, only $14 \%$ of the identified studies utilized nursing theory or conceptual framework ( $\mathrm{n}$ $=8)$.

\subsection{Study Design}

Sixty-three percent $(63 \%)$ of the studies utilized a quantitative approach $(\mathrm{n}=$ 36); whereas, $18 \%$ of the revised articles used a qualitative approach $(n=10)$. Almost $19 \%$ of articles were literature reviews $(n=11)$.

\subsection{Funding Source}

Funding was reported in $25 \%$ of the studies $(n=14)$. This funding was primarily through Hamad Medical Corporation (HMC). No funding or no specification of the source of funding was found in $75 \%$ of the studies $(n=43)$. None of the articles noted an external regional or international source of funding. This might be due to the availability of internal or local funding sources, which removes any serious motivation to apply for external funding.

\subsection{External Collaboration}

Nursing research in Qatar has largely been done in collaboration with other disciplines $(60 \% ; n=34)$. This collaboration was mostly with physicians $(65 \%)$, allied health professionals (15\%), and pharmacists (12\%). The remaining $8 \%$ of collaborative articles included multiple professions. Forty percent (40\%) of the 57 articles included in this review were written solely by nurses $(n=23)$.

\subsection{Research Topic}

Clinical practice issues were the focus of $42 \%$ of the revised studies $(n=24)$. This was a favorite topic for nurses, especially when conducting research studies in collaboration with physicians. The remaining $58 \%$ of the revised articles focused on five main topics: nursing education $(17.5 \% ; \mathrm{n}=10)$; public health $(16 \%$; $\mathrm{n}=$ $9)$; nursing management $(12 \% ; n=7)$; occupational health $(9 \% ; n=5)$; and sociocultural issues $(3.5 \% ; \mathrm{n}=2)$.

\subsection{Study Participants}

The results of this review indicated that revised studied population included participants from hospitals $(63 \% ; \mathrm{n}=36)$, community settings $(18 \% ; \mathrm{n}=10)$, and academic settings, such as nursing students $(7 \% ; n=4)$. The remaining $12 \%$ of the included studies were literature reviews papers $(n=7)$.

\section{Discussion}

\subsection{History of Research Development}

The present review paper could be considered worthy for nursing scholars in- 
ternationally especially for those in the Arab world because it evaluates and tracks the development of nursing research in Qatar. The results of this review revealed that the evolution of nursing research in Qatar is very recent; real scientific research work did not start until the 2000s. The growth of scientific research in the twentieth century has matched the development of nursing education in Qatar and the arrival of qualified expatriates from different regions in the world. It's difficult to compare the progress of nursing inquiry in Qatar to other states around the world, in particular with a lack of supporting evidence and huge differences in population, educational systems, and nursing professions, Eightyfour percent (84\%) of the research articles published over the last 15 years have been published in the previous five years $(\mathrm{n}=48)$, and $87 \%$ of the articles have been published in peer-reviewed journals $(n=50)$.

\subsection{Factors Affecting Research Development}

The 16-fold growth rate in research in Qatar over the last five years happened due to several changes and challenges in the healthcare system. These changes including social acceptance of nursing, technological advancements such as availability of access to regional and international journals, consumer demands of high-quality care, and emergent of complex bioethical dilemmas. Such environmental requires that nurses should be educationally qualified, capable of transforming evidence into practice in order to satisfy the needs of the clients from different backgrounds as well as deliver the best quality of care.

\subsection{Importance of Nursing Education}

Nurses with higher academic qualifications (such as those with master's and doctoral degrees) are more competent to expand and refine nursing research than other nurses with lower educational qualifications [7]. Nelms and Lane illustrated that in 1965 the American Association of Colleges of Nursing documented that it is imperative that to prepare nurses with essential knowledge in nursing, psychology, sociology, humanities and other health sciences fields in order to be able to think creatively, critically and find solutions to the complex and diverse nursing practices [14]. Recent trends in hiring highly qualified nurses and Academic Health System (AHS) could be another reason for the research boom in Qatar over the past few years [15]. This can be seen in the present study wherein $40 \%$ of authors had doctoral degrees in nursing, and $26 \%$ of them had a master's degree.

\subsection{Hamad Medical Corporation (HMC) Status}

In the last few years, HMC started and maintained its dynamic process of transformation that directed toward upgrading its clinical settings into factual Academic and Research Health Centers [15]. Establishing a successful Academic Health System is the ultimate goal of HMC. Such academic system can make connections between research, education and clinical practices, as well as can empower HMC by linking relevant academic partners and stakeholders in health 
arena with HMC. Nowadays, HMC has partnership agreements with several academic organizations in Qatar as well as around the world such as Sidra Medical and Research Center (SMRC), Qatar University, College of the North Atlantic-Qatar, Weill Cornell Medical College in Qatar (WCMC-Q), the University of Calgary-Qatar, and numerous primary health care centers [15].

\subsection{Contribution of Other Disciplines in Nursing Science}

Nursing scholars reported that researchers from other disciplines played a major role in establishing the early foundation of nursing knowledge through conducting of different studies that contribute to the nursing field [7]. This happens because most of the early nurses were not qualified to conduct research [16]. Beginning with the Gold Mark Report in 1923, non-nurses became involved in studying nursing related issues [17]. The process of "living, learning, and working" that adopted by numerous nurses is borrowed from the sociologists [18]. The research conducted by sociologists and behavioral scientists added to their respective bodies of knowledge but did not necessarily expand nursing's body of knowledge [19]. This is reflected in the current body of nursing literature based in Qatar; 60\% of the nursing research from Qatar has been done in collaboration with other disciplines, and only $40 \%$ has been done by only by nurses.

\subsection{Research Focus Area}

In the Canadian context, more than half of the conducted studies were addressed health promotion, health issues, and health service organization [16]. Few Canadian studies have investigated instruments' development, research dissemination, and utilization, environment, in addition to patient safety [16]. Australian authors focused mainly on the nursing education practice, as well as other professional topics [20]. In 2013, Dr. Khalaf found that nursing management was the most researched area in Jordan, followed by health promotion. On the other hand, nursing education, the gap between practice and education, best strategies in teaching and learning were received little attention in the Jordanian literature [13]. The current literature review indicated that the highest percentage of studies conducted in Qatar was focused on clinical practice issues, especially in collaboration with physicians. Nursing education (17.5\%), public health (16\%), nursing management (12\%), occupational health (9\%), and sociocultural studies (3.5\%) were also investigated.

\subsection{Research Setting and Context}

Most studies in Qatar were conducted in hospital settings (63\%). This may be because most of the researchers were working in hospital settings (88\%). Other studies recruited the participants from community settings (12\%), academic settings (8\%), as well as community settings (5\%), while $7 \%$ were literature reviews with no sample identification. These results are congruent with the Khalafs' study (2013). Moreover, Borbasi and colleagues' study reported that major 
health issues were received little attention in the Australian literature because the collected data were used mainly to describe nurse and patients [20]. While Moreno-Casbas recommended that nursing research should pay more attention to the clinical issues and patients' needs [21]. Nevertheless, current research is more associated with the nursing profession instead of clients' needs.

\subsection{Research Theoretical Framework}

Analysis of all the research studies done in Qatar showed that only $14 \%$ of them utilized a conceptual or theoretical framework that derived from nursing field. Similarly, in the Jordanian context, Khalafs' study revealed that only a few studies (11\%) used a theoretical framework from nursing field [13]. On the other hand, Bond and colleagues reported that about half of the revised studies in their literature review utilized nursing theoretical or conceptual framework [22]. Other scholars like Barrett [23] and Fawcett [24] documented that conducting nursing studies depending on theories from fields other than nursing will not make any progress in nursing science, skills, nor practice.

\subsection{Research Design}

Walker reported that descriptive and correlational designs can be set as the baseline for future research in the same field and can promote nursing profession development; however; there is a massive need for experimental or interventional research designs [25]. Sixty-three percent (63\%) of the authors of articles revised for this study selected quantitative approach for their studies. The qualitative approach was used in $18 \%$ of the articles, and the remaining $19 \%$ of reviewed articles were literature reviews. These results are comparable to the previous literature results in different countries [13] [20] [26].

\subsection{Funding Source}

It has been reported that European nursing research is funded by three major methods: public sector fund; non-profit organizations; and National Nurses' Associations (NNAs) [11]. The authors' reported that Canadian national organizations are responsible for funding nursing research in Canada [16]. Concerning Arab world, nursing research fund in Jordan can be obtained from national and international organizations [13]. In Qatar, most of the revised studies (75\%) did not mention the specific source of fund. The rest studies (25\%) were mainly obtained fund through the Medical Research Center (MRC) at HMC. No external regional or international funding was specified, which might be due to the availability of internal funding sources and the resultant lack of serious motivation to apply for funding. Although, funding of researchers can come from the Centers or the institutes where the researchers are conducted for instance; Qatar University. Researchers can also be granted by governmental agencies and councils such as Qatar National Research Fund (QNRF), SMRC, HMC, Barwa \& Qatari Diar Research Institute (BQDRI), and other funding facilities [27]. 


\section{Limitations and Recommendations}

While this literature review has presented information about nursing research in Qatar, in-depth analysis of the articles were not possible due to the massive variability in the articles reviewed. This might be considered as a limitation. Therefore, future work on the quality of published research and contribution to nursing practice is highly recommended. While the authors of this article have done an exhaustive search, they may have missed some eligible publications, which may also limit the findings of this study. Dr. Khalaf strongly recommended building local research databases for published nursing studies all states over the world; such databases could help in establishing priorities for nursing research at the national level, revising what has been explored in the past, and suggest recommendations for future research topics that may build up a robust nursing knowledge [13]. If these strategies are successfully implemented, they will promote nursing education, research, practice, and the overall nursing profession in Qatar and the Middle East region. Clinical relevance includes investigations about regional needs, primary care, as well as community-based services (like rehabilitation, geriatrics, and maternity services). Building collaboration affairs between academic institutions and clinical settings (such partnerships) can aid in determining research areas that required immediate attention [20]. Research utilization that incorporates implementing research results in the clinical practice is the most important step to advance the nursing profession.

\section{Conclusions}

This study was modeled on Dr. Khalaf's study [13]. It was found that only a few studies were carried out by nurses in Qatar. Research characteristics and authorship were analyzed, including what and how nurses are conducting research studies, with whom they are doing research, where they are conducting their research, and whether or not they receive funding.

The results indicate that the publishing rate of nurses has increased 16-fold between 2000 and 2015. Nurses in Qatar have published predominantly in peerreviewed journals. Clinical practice remained the favorite topic of research. A low percentage of research was funded, and nurses received little national grant funding. The increase in the number of post-graduate nurses in Qatar has positively affected the development of research, in particular with the establishment of the University of Calgary campus in Qatar (UCQ) in 2007 and the introduction of undergraduate and graduate programs which are sponsored by HMC and focus on Nursing Leadership and Oncology [28].

\section{Implications for Nursing and Health Policy}

Today's sophisticated, multifaceted healthcare challenges are not amenable to "isolated-islands" research approaches, where each profession/discipline is conducting their research. Building and sustaining nursing research infrastructure considered as a top priority for nursing leaders (in collaboration with other disciplines), academic bodies, and Ministry of Public Health (MoPH) in Qatar. 
Serious effort should be made to encourage nurses to study, implement, and utilize evidenced-based research by providing administrative support as the most influencing and facilitating factor for research implementation and utilization. Strategies need to be put in place to encourage the dissemination of research by providing professional writing assistance, conducting evidenced-based practice workshops and supporting nurses to attend and contribute to national, regional and international conferences.

Funds should be made available by governments through funding organizations for increased support of nursing and healthcare research priorities. An appraisal of research capability and outcomes needs to be conducted periodically to come up with recommendations to stakeholders and government for any necessary action plan.

\section{Acknowledgements}

Hamad Medical Corporation (HMC), Qatar provided facilities and support for this project. However, this research received no specific grant from any funding agency in the public, commercial, or not-for-profit sectors.

\section{References}

[1] Parahoo, K. (2014) Nursing Research: Principles, Process and Issues. Palgrave Macmillan, London.

[2] Nieswiadomy, R.M. (2011) Foundations in Nursing Research. Pearson Higher, New York.

[3] Nursing AAoCo (2003) Faculty Shortages in Baccalaureate and Graduate Nursing Programs: Scope of the Problem and Strategies for Expanding the Supply.

[4] Nursing AAoCo (2006) AACN Task Force on the Revision of the Research Position Statement: American Association of Colleges of Nursing.

[5] Polit, D.F. and Beck, C.T. (2013) Essentials of Nursing Research: Appraising Evidence for Nursing Practice. Lippincott Williams \& Wilkins, Philadelphia.

[6] Grove, S. and Burns, N. (2005) The Practice of Nursing Research: Conduct, Critique, \& Utilization. Saunders, St. Louis.

[7] Rhodes, M.K., Schutt, M.S., Langham, G.W. and Bilotta, D.E. (2012) The Journey to Nursing Professionalism: A Learner-Centered Approach. Nursing Education Perspectives, 33, 27-29. https://doi.org/10.5480/1536-5026-33.1.27

[8] Alligood, M.R. (2013) Nursing Theorists and Their Work. Elsevier Health Sciences, Amsterdam.

[9] Mackey, A. and Bassendowski, S. (2017) The History of Evidence-Based Practice in Nursing Education and Practice. Journal of Professional Nursing, 33, 51-55. https://doi.org/10.1016/j.profnurs.2016.05.009

[10] Keating, S.B. (2014) Overview of Nursing Education: History, Curriculum Development Processes, and the Role of Faculty.

[11] Tierney, A.J. (2005) Editor Nursing Research: Progress and Challenges. Paper Presented at the Conference on Nursing and Nursing Research.

[12] Boswell, C. and Cannon, S. (2012) Introduction to Nursing Research. Jones \& Bartlett Publishers, Burlington.

[13] Khalaf, I. (2013) Development of Nursing Research in Jordan (1986-2012). Interna- 
tional Nursing Review, 60, 461-468. https://doi.org/10.1111/inr.12042

[14] Nelms, T.P. and Lane, E.B. (1999) Women's Ways of Knowing in Nursing and Critical Thinking. Journal of Professional Nursing, 15, 179-186. https://doi.org/10.1016/S8755-7223(99)80039-8

[15] AHS (2011) About HMC Academic Health System. http://ahs.hamad.qa/en/about/about.aspx

[16] Nursing CAoSo (2008) Nursing Research in Canada: A Status Report. http://www.cfhi-fcass.ca/migrated/pdf/nursingrescapfinalreport_eng_finalb.pdf

[17] Gebbie, K.M. (2009) 20th-Century Reports on Nursing and Nursing Education: What Difference Did They Make? Nursing Outlook, 57, 84-92. https://doi.org/10.1016/j.outlook.2009.01.006

[18] Abdellah, F.G. and Levine, E. (1965) Better Patient Care through Nursing Research. International Journal of Nursing Studies, 2, 1-12. https://doi.org/10.1016/0020-7489(65)90013-1

[19] Henderson, V. (1956) Research in Nursing Practice-When? Nursing Research, 4, 99. https://doi.org/10.1097/00006199-195602000-00001

[20] Borbasi, S., Hawes, C., Wilkes, L., Stewart, M. and May, D. (2002) Measuring the Outputs of Australian Nursing Research Published 1995-2000. Journal of Advanced Nursing, 38, 489-497. https://doi.org/10.1046/j.1365-2648.2002.02210.x

[21] Moreno-Casbas, T. (2005) Nursing Research in Europe, Scoping Report. Institute of Health Carlos III, Madrid.

[22] Bond, A.E., Eshah, N.F., Bani-Khaled, M., Hamad, A.O., Habashneh, S., Kataua, H., et al. (2011) Who Uses Nursing Theory? A Univariate Descriptive Analysis of Five Years' Research Articles. Scandinavian Journal of Caring Sciences, 25, 404-409. https://doi.org/10.1111/j.1471-6712.2010.00835.x

[23] Barrett, E.A.M. (2002) What Is Nursing Science? Nursing Science Quarterly, 15, 5160. https://doi.org/10.1177/089431840201500109

[24] Fawcett, J. (1999) The State of Nursing Science: Hallmarks of the 20th and 21st Centuries. Nursing Science Quarterly, 12, 311-315. https://doi.org/10.1177/089431849901200411

[25] Walker, W. (2005) The Strengths and Weaknesses of Research Designs Involving Quantitative Measures. Journal of Research in Nursing, 10, 571-582. https://doi.org/10.1177/136140960501000505

[26] Bohman, D.M., Ericsson, T. and Borglin, G. (2013) Swedish Nurses' Perception of Nursing Research and Its Implementation in Clinical Practice: A Focus Group Study. Scandinavian Journal of Caring Sciences, 27, 525-533. https://doi.org/10.1111/j.1471-6712.2012.01058.x

[27] QNRF (2016) Qatar Research Institutions. http://www.qnrf.org/en-us/Funding/Collaboration/Qatar-Research-Institutions

[28] UCQ (2015) About University of Calgary in Qatar. http://www.ucalgary.edu.qa/ 
Submit or recommend next manuscript to SCIRP and we will provide best service for you:

Accepting pre-submission inquiries through Email, Facebook, LinkedIn, Twitter, etc. A wide selection of journals (inclusive of 9 subjects, more than 200 journals)

Providing 24-hour high-quality service

User-friendly online submission system

Fair and swift peer-review system

Efficient typesetting and proofreading procedure

Display of the result of downloads and visits, as well as the number of cited articles Maximum dissemination of your research work

Submit your manuscript at: http://papersubmission.scirp.org/

Or contact ojn@scirp.org 